\title{
América Latina, cambio de época y destino histórico común. Notas de estudio sobre la actual pluralidad cultural y religiosa"
}

\author{
Vitor Hugo Mendes**
}

Recibido: 8 de febrero de 2013 • Aprobado: 28 de mayo de 2013

\section{Resumen}

Los cambios sociales han trascendido al ámbito religioso, por eso este texto busca acercarse a los cambios que enfrenta la realidad latinoamericana y del caribe, de igual manera presenta algunos barruntos en lo que respecta a la inteligencia de la fe en un contexto plural; máxime cuando la construcción de identidad del continente es traspasada por la diversidad cultural. Esto deviene inexorablemente en pluralismo religioso, desde los desafíos y posibilidades que plantea la superación de la homogeneidad católica.

Palabras clave: América Latina, el Caribe, Aparecida, cultura, diversidad, pluralismo.

* Conferencia presentada en el XI CONGRESO DE TEOLOGÍA DE LA UNIVERSIDAD SANTO TOMÁS: TEOLOGÍAS Y CONTEXTOS SOCIALES EN AMERICA LATINA, Bogotá, Colombia, 23 al 25 de octubre de 2013.

** Doctor en Educación; Magister en Teología Sistemática; Magister en Educación, Historia y Política; Doctorando en Teología; Secretario Ejecutivo de Cultura y Educación CELAM; Miembro del Equipo de Reflexión teológica del CELAM; Profesor del ITEPAL; Presbítero de la Diócesis de Lages, Santa Catarina, Brasil. Correo electrónico: culturayeducación@celam.org / mendesvh@terra.com.br 


\title{
Latin America, time of change and common historical destiny. Working papers on the current cultural and religious plurality
}

\begin{abstract}
Social changes have transcended to the religious circle, this is why this article seeks to approach changes faced by Latin American and Caribbean reality, likewise it presents some indications with regards to the intelligence of faith in a plural context; especially when the construction of the continent's identity is transferred by cultural diversity. Inexorably this turns into religious pluralism, from the challenges and opportunities posed by overcoming catholic homogeneity.
\end{abstract}

Keywords: Latin America Latina, the Caribbean, Aparecida, culture, diversity, pluralism

Cuando el Documento de Aparecida afirma que "vivimos un cambio de época, y su nivel más profundo es el cultural" (Aparecida, 44) delimita, en muchos aspectos, el escenario fundamental en donde nos encontramos en las actuales circunstancias. En tal perspectiva, según parece, en el movimiento cultural, se visibilizan los trazos fundamentales de la dinámica de nuestra contemporaneidad, en gran medida inspirada por el sentido plural de todas las cosas. De manera general, en lo que las culturas engendran se explicitan las diversas disyuntivas de orden económico y político, fenómeno que alcanza al ámbito religioso. A la luz de esa complejidad, a veces descrita con la palabra globalización -para indicar la realidad social en su dinámica actual (Aparecida, 43)-, se busca identificar los diferentes retos que se presentan en el horizonte de la Misión Continental y Permanente, entendida como Nueva Evangelización.

Dada la amplitud de la problemática y el perfil pastoral de la V Conferencia del Episcopado Latinoamericano y del Caribe celebrada en Aparecida (2007), la tipificación de las vicisitudes históricas en proceso, caracterizadas en su contorno cultural, se muestra un atajo necesario para describir los cambios en curso. Sin embargo, la densidad de esta realidad ordenada en torno a la expresión "cambio de época" remite a una cuestión fundamental que requiere mayor profundización.

El presente estudio, al modo de aproximación, trata de incursionar por esos senderos. Busca identificar la extensión y la profundidad de esas transformaciones por las cuales pasa la situación Latinoamericana y Caribeña, como también, 
precisar algunas indicaciones en lo que respeta a la vivencia e inteligencia de la fe en un contexto de pluralidad. Tratando de profundizar esas cuestiones, en este trabajo dirige sus esfuerzos en comprender algunos aspectos de los cambios ocurridos con referencia a las transformaciones en el ámbito de la religiosidad latinoamericana.

Bajo esta perspectiva, valoramos que el ámbito religioso fue y sigue siendo un componente indispensable para comprender la conformación de la vida social - económica, política, cultural- en la realidad Latinoamericana y Caribeña. Sin embargo, en estos días, el ámbito religioso adquiere expresiones muy diversificadas $\mathrm{y}$, se puede decir, en proporciones nunca antes previstas en este contexto.

En general, la religiosidad se muestra como un fenómeno complejo, sobre todo por su pluralismo religioso. En este aspecto, el diálogo interreligioso, el ecumenismo y hasta el mismo desarrollo de la teología de las religiones se confronta con condicionamientos bastante específicos en el contexto regional ${ }^{1}$. En este sentido, entendemos que una mirada desde el cristianismo católico no puede hacerse sin darse cuenta de esa nueva situación en América Latina y el Caribe. Se trata de aspectos que de hecho deben ser reflexionados, sobre todo, cuando interesa considerar la acción del CELAM y la propuesta de una Misión continental como un posible factor de integración regional (Mendes, 2013).

En particular, se piensa con atención en lo que urge Aparecida al considerar la riqueza de las culturas y la diversidad presente en el Continente. El gran desafío evangelizador, afirma el documento conclusivo, es "la posibilidad de que esta diversidad pueda converger en una síntesis que, envolviendo la variedad de sentidos, sea capaz de proyectarla en un destino histórico común" (Aparecida, 43).

\section{América Latina y El Caribe: la búsqueda por una identidad realmente plural}

La diversidad originaria presente en la Patria Grande, América Latina, a lo largo de los siglos fue fuertemente dominada por una presencia externa, marcadamente colonizadora. Bajo ese control, sometidos a la lógica del dominio fundador que

1 Según Paviani, “el concepto de región, además de la dimensión natural, además de envolver solo, paisaje y otros accidentes geográficos engloba aspectos lingüísticos y antropológicos. En otros términos, cuando se habla en región, de modo general, se define identidades, costumbres, tradiciones, comportamientos lingüísticos e, igualmente, obras técnicas y artísticas" (2010, p. 38). 
alcanzó a llegar a estas tierras del "Nuevo Mundo", los que eran diferentes poco a poco fueron equiparados a la condición igual de "subcultura". Se fabricó una homogeneidad que privilegió el (des)orden de los conquistadores impulsados por su "cultura". Esa mirada desde afuera sobre las Indias Occidentales prevaleció y se impuso, casi siempre de modo beligerante, bajo la fórmula civilizatoria que se utilizó para lidiar con los pueblos autóctonos, los grupos africanos y con todos los "serviles" que aquí llegaran.

Voces disidentes e insurgentes registrarán otras iniciativas y desearán otras posibilidades para estos pueblos y sus culturas. Sin embargo, aquellas contingencias significaban un factor más que secundario frente a los intereses económicos y políticos en juego. Hasta el auspicioso proyecto evangelizador -patrocinado por los Reyes Católicos-, muchas veces, sucumbió a las desventuras de una evangelización asociada al expansionismo exploratorio de las coronas ibéricas ${ }^{2}$.

Desde aquella hegemonía forastera, en estas tierras se fue tejiendo un largo período de historias de vida, de luchas y de resistencias, de movimientos de independencias y de construcción del Estado democrático. El encuentro y la forzosa convivencia de esas culturas -Pueblos Originarios, Pueblos Europeos, Pueblos Africanos y Gentes diversas-, engendrarán una realidad vital cuyos matices, tan diversos, generaran una cultura polisémica que aún reivindica los derechos de su identidad realmente plural.

A pesar de la conquista apropiadora y los sucesivos imperialismos culturales y económicos a que fue sometida la región a lo largo de años de subordinación, la idiosincrasia Latino Americana y Caribeña sostiene tradiciones propias y mantiene su carácter distintivo. En ese sentido, cada vez más esa misma geografía de otrora es dada a conocer a partir de sus muchas particularidades y diversidades, multiplicidades que diseñan diferentes modos de vivir y de valorar la vida, la naturaleza, la tierra, etc. Hoy es casi un consenso reconocer que nuestra latinidad ya "no se deja comprender de modo unidimensional" (Bombassaro, 2010). Con razón la expresión América Latina y El Caribe ya pertenecen a la jerga común para designar una realidad latina multíplice en sus correlatos colonizadores (ingleses,

2 “Es importante reconocer, afirma Tescaroli, que la llegada de la Iglesia a la Amerindia es completamente ambigua, como se refleja en las Bulas que durante 1493 emitió el papa Alejandro VI en favor de los Reyes Católicos de España. Es evidente que en estos documentos prevalecía el interés por una evangelización misionera en favor de los indígenas y aborígenes, pero también es claro que, por este motivo y por las teorías imperantes en la época sobre el supremo poder temporal del Papa, en dichas Bulas se concedía a los Reyes potestad, autoridad y jurisdicción sobre las tierras y pueblos descubiertos"' (1992, p. 144). 
franceses, holandeses). En diferentes perspectivas se evidencia el carácter multiétnico y pluricultural del Continente (Santo Domingo, 243).

Ese paulatino reconocimiento de una identidad realmente plural, en América Latina y El Caribe, no deja de expresar un significativo avance en lo que respecta a la comprensión de una realidad históricamente compleja ${ }^{3}$. De hecho, solamente por fuerza de una ilusoria uniformidad o de un examen superficial fue posible sostener una pretendida homogeneidad socio-cultural y religiosa, política y económica. Sin embargo hay un largo camino por recorrer.

Si por un lado, como resalta Aparecida, el reto es que la "diversidad pueda converger en una síntesis que, envolviendo la variedad de sentidos, sea capaz de proyectarla en un destino histórico común" (Aparecida, 43); de otro lado, ese sentido compartido de la historia, de alguna manera, debe encontrar instrumentos capaces de garantizar vida y dignidad para todos, esto es, respetar las diferencias, sembrar la igualdad y promover un sentido humano-ecológico sostenible. En suma, se trata de dar coordinación a una colectividad que se reconoce como diversidad, pero que se hace capaz de cooperar en una convivencia social íntegra, comunitaria y solidaria. Las huellas de ese arquetípico, patrimonio de los Pueblos de la Pachamama, aún están presentes y aún tiene posibilidades de alcanzar un rostro propio, un talante político que genere otro mundo posible 4 .

Bajo esa perspectiva, rescatar las distintas particularidades latinoamericanas con miras a la unidad común no puede significar un mero remitirse a los orígenes ancestrales, es decir, retroceder a un pasado que se distancia en el tiempo. El sentido recuerdo de esa historia requiere asumir una identidad plural dinámica que, en perspectiva realmente sapiencial, sepa discernir, dialogar, convocar y contemporizar con su propia realidad, lo que implica, también, alzarse al futuro.

3 “Dentro deun gigantesco cuadro geográfico, más de 21 millones de kilómetros cuadrados viven casi 600 millones de habitantes: es la América Latina, multiétnica y multicultural. Hay una américa Latina blanca: Argentina, Uruguay, Sur de Brasil y regiones de Chile, Colombia, Costa Rica y Cuba. Hay una América Latina India: Perú, Bolivia, Ecuador, México, Centroamérica, regiones de Colombia, Paraguay, Venezuela. Hay una América Latina Negra: Centro y norte de Brasil, Antillas, Guayanas, regiones de Colombia y Centroamérica. Un cálculo aproximado presenta el siguiente mosaico Latinoamericano: $38 \%$ de indios y mestizos; $33 \%$ de blancos; $28 \%$ de negros y mulatos y un uno por ciento de asiáticos" (Reyes, 2012).

4 En este sentido, es interesante observar que, en muchos países latinoamericanos, la reciente celebración del bicentenario de la Independencia fue, en gran medida, la manifestación de un sentimiento común de pertenencia y liberación. Las líneas de jurisdicción nacional parece que significan menos que el sentido de una territorialidad simbólica más amplia, sin fronteras que se quiere y se busca. 
Frente a este cuadro de referencias, una realidad efectivamente nueva y que se debe tomar en consideración, es que la rica variedad de culturas, pueblos y naciones que constituyen la región, ahora ya resultan en una presencia social -política y económica- que se expande en importancia y responsabilidades mucho más allá de sus fronteras. Además de la diversidad cultural y el exclusivo patrimonio ecológico, las nuevas configuraciones de la economía posicionan a algunos países; también la región en un contexto de desarrollo que ya se define, de manera afirmativa, en relación a emprendimientos de escala mundial.

Datos recientes del Banco Mundial indican que "actualmente los porcentajes de la población de clase media y de pobres en América Latina están igualados. Esta situación contrasta con la que prevaleció, durante un largo periodo, hasta hace casi 10 años, cuando el porcentaje de pobres equivalía aproximadamente a 2,5 veces el de la clase media". Esas tasas de crecimiento revelan cambios importantes en la movilidad social; los mismos análisis apuntan para el hecho de que estos cambios pueden alterar significativamente el contrato social en la región. En la medida en que el área se convierte en un espacio en el cual pasa a predominar un perfil de clase media (Ferreira, 2013), nuevos ajustes de orden social pasan a ser necesarios.

Todos esos indicadores son suficientes para evidenciar un contexto regional en movimiento, transformación y progresiva expansión. Los datos, en general casi siempre optimistas con el crecimiento en el ranking de los emergentes, pueden servir para diferentes tipos de análisis, aunque también para apologías político-económicas. No obstante, el campo real de las posibilidades está condicionado a que, efectivamente, las opciones de integración, desarrollo y crecimiento sean de hecho incluyentes y sepan convocar a una amplia participación de la sociedad $^{5}$. Fundamental es que a los ajustes económicos corresponda una justa y equitativa redistribución de la renta.

En lo que sigue, tratamos de reflexionar el significado y el impacto de algunos cambios en el ámbito de la religiosidad en virtud de considerar, de manera dinámica, la actual situación en Latinoamérica y El Caribe.

5 En esta línea de reflexión y aporte, vale la pena conferir Boff (2013) cuando trata de presentar lo que llama de Constitucionalismo Ecológico con respeto a las Constituciones de Ecuador y Bolivia. Según Boff, esto pone los referidos países en singular condición de desarrollo; de hecho, lo que se hizo en ámbito jurídico, configura un aporte significativo en orden a una valoración integral de la vida en extensión planetaria. 


\section{Cristianismo y religiosidad en las actuales circunstancias: la situación Latinoamericana y Caribeña}

Recientes estudios tratan de considerar los vínculos complejos entre religión y sociedad (Silva, Bellotti, Campos, 2010) en América Latina. Sin dudas, el ámbito religioso ha tenido una importancia fundamental cuando se trata de perfilar la identidad regional del Continente. Las cifras dicen que en los finales del siglo XX, los cristianos sumaban el $93 \%$ de la población. Actualmente en torno de $40 \%$ del Cristianismo católico mundial está concentrado en esta región (Europa, por ejemplo, representa apenas el 23\%). A la vez, análisis significativos tratan de comprender el creciente proceso de pluralización religiosa (Cipriani, Eleta, Nesti, 2000; Libanio, 2008; Merino, 2010).

Ese breve índice de trabajos permite visualizar que con su realidad de transformaciones diversas, también en lo que concierne al mundo religioso, América Latina vive un gran movimiento. Con esa coyuntura dislocada, constantemente resuenan innumerables preguntas respecto al futuro del Cristianismo, lo que deja pendiente, el desafío de responder a la situación del catolicismo frente al creciente pluralismo religioso (Parker, 2005).

Teniendo en cuenta esta realidad tomamos como ruta, en la medida de lo posible, una ruta alternativa que nos permite avanzar en el conocimiento de esta realidad. Carlos Palácio (2004), por ejemplo, en su intento por comprender ese complejo escenario religioso, ofrece un tipo de molde para la problemática que considera un itinerario relativamente amplio de forma breve. Se trata de una interpretación que, de modo general, remite a visualizar las transformaciones que lograron desajustar el rumbo de la cultura occidental y que inevitablemente se reflejan en el Cristianismo (Mendes, 2004). Según considera el autor, dos grandes movimientos han transformado significativamente el horizonte de la sociedad occidental: de un lado, una profunda transformación en la esfera cultural; por otro lado, un inusitado cambio de orden religioso (Palácio, 2004). Tales interferencias ponen en grave cuestionamiento la arquitectónica occidental de civilización. En principio, dada la reconocida penetración/asimilación de las vicisitudes occidentales en la formulación del Cristianismo, la descentralización de esa paradigmática cosmovisión sigue por repercutir, como crisis, en el corolario religioso.

Teniendo en cuenta esta dual metamorfosis, con referencia al primer aspecto, afirma el autor, una mirada en la 
"rapidez vertiginosa con que en poco más de tres décadas se modificó instituciones, hábitos, costumbres, valores, etc. en la sociedad occidental, encontramos los indicios más evidentes de que, esas transformaciones, atinge no apenas los fenotipos de la 'visión cultural del mundo', más modifican sus genotipos y nos colocan, por lo tanto, delante una verdadera mutación de la cultura" (Palácio, 2004).

Es decir, en estas distintas manifestaciones de orden cultural, la univocidad y la exclusividad totalizante asegurada en la perspectiva occidental, fue definitivamente rota. Delante de una fecunda diversidad cultural, la ortodoxia uniformadora occidental se ve cuestionada, relativizada ante la posibilidad de que otras culturas se establezcan como alternativa para afrontar problemas de la vida práctica así como los dilemas de la propia existencia. La realidad del otro pone en relación la verdad y sus criterios, como también, cambia y redefine el horizonte posible de una cosmovisión tematizada en sentido plural (Mendes, 2006).

Con base en esa radical transformación cultural, Palácio (2004) sitúa el correspondiente cambio religioso de la sociedad contemporánea. En su interpretación,

Tres factores parecen estar configurando esa 'situación espiritual' en la cual puede ser detectada la metamorfosis del religioso en la sociedad occidental: el factor cultural de la 'virada antropocéntrica' de la modernidad, el sorprendente retorno del religioso reprimido, y el fenómeno del pluralismo religioso como uno de los resultados del encuentro entre culturas diferentes. La crisis es el resultado de la interacción de esos tres factores.

Emancipado de cualquier heteronomía, el giro antropocéntrico en la modernidad, promovió la creciente diferenciación de las esferas social y religiosa, y en consecuencia, la total autonomía de la sociedad con relación a la Iglesia. La razón fundamental de la religión ya no es una justificación social en las instancias del orden civil. Tal dislocamiento no tardó en promover la inmanencia en visible desprestigio de la transcendencia. La vida pasa a ser efectiva en ese nivel, en el esfuerzo de bastarse en sí misma. Considera Palácio, allí reside el impase moderno, o sea: tanto más parece insuficiente el intento de dar sentido a la existencia en su performance horizontal, tanto más recalca un vacío de sentido de largo alcance. De toda manera, lo que se debe resaltar es que hay un cambio significativo en lo que refiere a ubicar el religioso y la religión en el contexto moderno.

Un segundo factor considerado en la crisis de la religiosidad, consiste en "el retorno del religioso de manera anárquica y bajo las formas más heterogéneas [...]". Según nuestro autor, "es difícil explicar las causas de esta inesperada efervescencia religiosa. Todavía no se puede negar que ella tenga alguna relación con 
la crisis de sentido que afecta no sólo a los individuos, sino a la sociedad como un todo" (Palácio, 2004).

Se trata de un fenómeno nuevo y lleno de ambigüedades. El autor en cuestión ya no se refiere a las formas usuales de las religiones tradicionales. Todo se procesa en una miscelánea de perspectivas y prácticas que traduce el sentido del hombre religioso en una diversidad sin límites. "Para dar cabida a tal heterogeneidad es preciso dilatar de tal forma el concepto de 'religioso' que se pierde su sentido original. De allí la ambigüedad del fenómeno y la lucidez para discernir ese sorprendente 'imprevisto religioso" (Palácio, 2004).

Finalmente, el tercer factor corresponde a un evento que deriva de un inevitable encuentro de las grandes religiones: el pluralismo religioso. Ese aspecto, en particular, contempla diferentes implicaciones y enfrenta algunos dilemas. Para Palácio,

“En el encuentro entre las grandes religiones de la humanidad, la aparente univocidad del lenguaje (divino, transcendencia, Dios, realidad última, experiencia mística, etc.) esconde experiencias diferentes de Dios, de relación del sujeto con Dios y con el mundo que no son intercambiables" (2004).

Aunque el encuentro de las religiones favorezca la aproximación y, a veces, la convivencia, esa misma experiencia resalta las diferencias, como también, reclama intensamente la tolerancia religiosa, lo que no siempre encuentra actitud y disponibilidad. Tal realidad diseña una situación presente realmente compleja y dependiente del diálogo posible.

Con esa breve descripción de la metamorfosis del cambio cultural y lo que deriva - de los tres aspectos indicados-como transformación religiosa, tenemos un cuadro circunstancial de la complejidad que implica, en el ámbito social y religioso, el presumido "cambio de época" en el horizonte de un cambio cultural. En el contexto regional de América latina y El Caribe ese fenómeno asume características muy específicas. Como sugiere el autor, lo fundamental consiste en discernir las situaciones para recomponer la experiencia (Palácio, 2004).

Ese aspecto, entre otros, requiere preservar lo específico regional, o sea, implica considerar en el ámbito religioso todo lo que significa la constitución de un mundo que tiende a configurarse de manera pluricultural, pluri-racial, pluricéntrico. Se trata de suponer una diferenciación que resulta de la propia crisis de la uniformidad occidental, un fenómeno multifocal que abre camino para una inculturación en la que hay que hacer caminos inéditos. 
Frente a esto, dos aspectos que resaltar. Por un lado, el reto de reconocer dentro del propio catolicismo las marcas de condicionamientos del pasado y la inercia tradicional, las cuales subsisten e impiden superar un excesivo eclesiocentrismo. Por otro lado, enfrentar de manera consecuente la reconfiguración de la matriz religiosa, sobre todo, en lo que resulta como sincretismo religioso.

De modo particular, en el caso de Brasil; Palácio considera que la cuestión del sincretismo religioso, incrustado en la vida social, podría significar un auténtico proceso de "inculturación de la fe". Todavía, esos aspectos que piden una nueva consideración de la pluralidad cultural y religiosa requieren, al menos, establecer un renovado diálogo con las culturas afros e indígenas en vista a reconocer que tienen aportes que deben ser considerados.

Todos esos aspectos, visualizados en su conjunto, permiten establecer un cuadro de referencias que, de manera previa, sirve como parámetro para la aproximación a la diversidad que caracteriza la realidad latinoamericana y caribeña. Lo que permanece como continuidad de la reflexión es la posibilidad de retomar las propuestas que, en diferentes perspectivas, se dirigen a orientar el diálogo interreligioso, en particular, la reflexión ecuménica ante la pluralidad presente en el contexto regional.

Interesa, particularmente, lo que pueda servir como referencia para indicar la participación y el aporte de las Iglesias en lo que respeta a la integración regional latinoamericana y caribeña. En este sentido, hemos de revisar la contribución del CELAM que, como institución, representa una importante iniciativa histórica en ese camino, como también, a partir de Aparecida, lo que pueda significar, en esta perspectiva, el proyecto de la Misión Continental y Permanente (Merino, 2009a).

\section{Palabras finales}

La oportunidad de profundizar estos aspectos introductorios de la temática permitió observar cómo ha crecido, en la última década, la producción analítica que trata de reflexionar sobre esta realidad pluricultural y multirreligiosa. En ese sentido, se buscó seguir un itinerario de conjunto que, dada la multiplicidad de referencias, se muestra más como indicativa de una tarea por realizar que propiamente un ejercicio que nos conduzca a síntesis y conclusiones.

Todavía, como se puede percibir en la situación religiosa en general y en la realidad Latinoamericana y Caribeña en particular, se encuentran desafíos concretos que, partiendo de la creciente pluralidad religiosa, exige reposicionar el 
diálogo interreligioso en caminos que aún deben ser abiertos y recorridos: vivimos en la región una infinidad de cambios en diferentes aspectos. Tal situación, sin dudas, exige al cristianismo, particularmente la confesión católica, participar de una interlocución compleja y difícil. Si por un lado hay que considerar las prácticas y experiencias orientadas a un ejercicio ecuménico, por otro, hay que ponderar lo que debidamente pertenece a una agenda de trabajo que, a su tiempo, incorpora los alcances y límites del desarrollo de una Teología de las Religiones que se hace en diálogo con la propia pluralidad (Miranda, 1994; Merino, 2009b).

Sin embargo, lo que parece fundamental tener en cuenta es que en el contexto Latinoamericano y Caribeño, el ámbito religioso -hasta por las mismas implicaciones de su manera de impostar la teología-, tiene un importante lugar social. En ese sentido, el re-encuentro con las particularidades de la región se presenta como una posibilidad abierta, como un camino que requiere proseguir el discernimiento del cristianismo católico en medio a la creciente pluralidad cultural y religiosa.

\section{Referencias}

Boff, L. (2013). Constitucionalismo ecológico na América Latina. IHU, UNISINOS, 10/05/2013. Recuperado: 04 de junio de 2013 desde: . http://www.ihu.unisinos. br/noticias/519994-constitucionalismo-ecologico-na-america-latina-artigo-deleonardo-boff

Bomassaro, L. C. (2010). Pensar a latinidade como experiência multicultural. En: Bombassaro, L. C. \& Vidal, S. P. Latinidade da América Latina. Enfoques filosóficos e culturais. São Paulo: Editora Hucitec,

CiprianI, R., Eleta, P., Nesti, A., (2000). Identidade e mudança na religiosidade Latinoamericana. Petrópolis: Vozes,.

Documento de Santo Domingo (SD). (1993). IV Conferencia General del Episcopado Latinoamericano. 2․․ Edición corregida. Bogotá: CELAM,

Documento de Aparecida (DA). (2007). Texto Conclusivo da V Conferencia Geral do Episcopado Latino-americano e do Caribe. Brasília: Edições CNBB; Paulinas; Paulus.

Parker, C. (2005). ¿América Latina ya no es más católica? Pluralismo cultural y religioso creciente. Revista América Latina hoy, Universidad de Salamanca, diciembre, Vol. 41. pp. 35-56.

Ferreira, F. (2013) H. G.; Julian Messina, Jamele Rigolini; Luis-Felipe López-Calva; Maria Ana Lugo; Renos Vakis. Panorámica General: La movilidad económica y el crecimiento de la clase media en América Latina. Washington, DC: Banco Mundial. Licencia: Creative Commons de Reconocimiento CC BY 3.0. 
Libanio, J. B. (2008). Crenças Religiosas, Fanatismo e Secularidade na América Latina. Revista Perspectiva Teológica, $\mathrm{n}^{\circ}$. 40. p. 55-76.

Mendes, V. H. (2004). Inteligência da fé em um contexto pós-metafísico: apontamentos para uma nova sensibilidade teológica. Dissertação de Mestrado. Porto Alegre: PUCRS,.

O sujeito da educação em um contexto pós-metafisico(2006). Porto Alegre: UFRGS, Tese (Doutorado em Educação) (2006) - Universidade Federal do Rio Grande do Sul, Porto Alegre.

. Posição pós-metafísica e inteligência da Fé: apontamentos para uma outra estética teológica (2008). Cadernos de Teologia pública, Edição no. 35, São Leopoldo, IHU-UNISINOS.

. Vaticano II: A modernidade da Igreja em um contexto de mudanças (2011). En: Revista Medellín, Vol. 37, nº. 144, Diciembre, Bogotá, p. 461-487.

. Nova Evangelização na Formação dos Presbíteros (2013). En: Boletín de la OSLAM. $\mathrm{n}^{\circ} .62$ Enero-julio. $16 \mathrm{p}$.

Presencia de la Iglesia en la ciudad y Evangelización de las Culturas (2012). En: Congreso Internacional de Pastoral Urbana, Dios vive en la ciudad. Ciudad de México: Anales,.

Miranda, M. de F. (1994). O encontro das religiões. Revista Perspectiva Teológica, $\mathrm{n}^{\circ}$. 26, pp. 9-26.

Merino, P. (2009a). Renovación misionera y diálogo ecuménico en Latino-américa: convergencias teológicas. ATUCSC 11.2. p. 313-332.

Merino, P. (2009b). Génesis, desarrollo y aspectos críticos de la teología pluralista de la liberación. En: Revista Teología, Tomo XLVI, n. 98 Abril. p. 79-94.

Merino, P. (2010). Diversidad religiosa y teología desde Latinoamérica: visión panorámica.En: Reflexiones Teológicas, $n^{\circ} . .6$, (57-82) Sep.-dic.. Bogotá, Colombia.

Palácio, C. (2004). O Cristianismo na América Latina. Discernir o presente para preparar o futuro. Revista Perspectiva Teológica, n. 36. p. 173-196.

Paviani, J. (2010). Região, experiência e cultura regional. En: BOMBASSARO, L. C.; VIDAL, S. P. (2010). Latinidade da América Latina. Enfoques filosóficos e culturais. São Paulo: Editora Hucitec. p. 37-45.

Reyes, M. A. (2012). Evangelización y Cultura em América Latina. Revista Culturas y Fe. Pontificium Consilium de Cultura. Civitas Vaticana, Vol. XX nº. 4. p. 245-249.

Silva, E. M.; Bellotti, K.; Campos, L. (2010). Religião e sociedade na América Latina. São Bernardo do Campo: UMESP.

Susin, L. C. (1990). Cur evangelizare: as razões da evangelização. Revista Perspectiva Teológica, Belo Horizonte, Vol. 56. p. 11-30.

Tescaroli, C. (1992). América Latina. 500 años de Evangelización. Lima: Editorial Sin Fronteras. 